\title{
Gingival Veneer: Non-esthetic to esthetic smile
}

\author{
Aditya Sinha ${ }^{1}$, Sankar Madhvan ${ }^{2}$, Shivamurthy Ravindra ${ }^{3}$, Sudhakara Bhat ${ }^{4}$ \\ ${ }^{1}$ Department Of Periodontics and Oral Implantology, K.D. Dental College \& Hospital, India \\ ${ }^{2}$ Department of Prosthodontics and Oral Implantology, Sree Anjaneya Institute of Dental Sciences, India \\ ${ }^{3}$ Department Of Periodontics and Oral Implantology, Sri Hasanamba Dental College \& Hospital, India \\ ${ }^{4}$ Department of Prosthodontics and Oral Implantology, Sri Hasanamba Dental College \& Hospital, India
}

\begin{abstract}
Periodontium along with its supporting tissues are damaged and destroyed by the various forms of gingival and periodontal diseases which leads to gingival recession, soft tissue defect in the esthetic region. When small volumes of tissue are being reconstructed then its possible to create esthetically satisfying and anatomically correct tissue contours, but this method is unpredictable when a large volume of tissue is missing. The unpredictability, healing time, discomfort and surgical costs make this option unpopular. The reconstruction of these areas with prosthesis like gingival veneer can be useful to correct the deformities remaining after the control of periodontal diseases, especially in the maxillary anterior region. This article aims to revisit the gingival veneer: its uses, advantages, disadvantages. The case discussed here highlights a clinical situation where the gingival veneer prosthesis helped in achieving optimum esthetics and patient satisfaction thus proving to be a feasible and simple treatment modality.
\end{abstract}

Keywords: Gingival mask, gingival slip, gingival veneer, party gums, periodontal surgery

\section{Introduction}

Gingival replacement prostheses may be used to replace tissue lost through periodontal diseases, surgical gingival procedures, trauma, ridge resorption or traumatic tooth extraction all of which can result in open inter dental spaces, elongated clinical crowns, phonetic problems as well as unanticipated expectoration during speech.[1]

A gingival veneer (or gingival veneer prosthesis) is defined as a prosthesis worn in the labial aspect of the dental arch, which aims to restore the mucogingival contour and esthetics in areas where periodontal tissues are deficient.[2]

Gingival veneers were first introduced in 1955 by Emslie and were used to mask the unesthetic appearance of gingival recession in a patient who underwent a gingivectomy.[3] In 1970, L'Estrange et al. reported on a number of patients that had worn gingival veneers for over 3 years. [4]

In the past gingival veneers not only have replaced lost tissues but have been also used as a vehicle for delivering topical medications such as topical fluoride, triamcinolone $0.1 \%$ in dental paste (in the treatment of desquamative gingivitis), and as a carrier for periodontal dressings. [4]

Porcelains, pink auto cure and heat-cured acrylics, composite resins and thermoplastic acrylics, as well as silicone-based soft materials are being used to make gingival veneers. A good case selection, with adequate oral hygiene being a key factor in the success of the gingival veneer.

The use of gingival veneers are as follows:-

Indications :-[2,5]

1) Exposed crown margins, and /or root surfaces, inter dental "black triangles", leading to poor esthetics

2) Food packing in inter dental spaces

3) Lack of saliva control

4) Impaired speech

5) Root dentine sensitivity

Contraindications :-[2,5]

1) Poor oral hygiene

2) Limited manual dexterity

3) High caries activity/risk

4) Incomplete periodontal therapy

5) Allergy to fabrication materials

\section{Case Report:-}

A 40 year-old female patient reported to the Department of Periodontics, Sri Hasanamba Dental college and hospital, Hassan with the complaint of receding and itching gums, food lodgment and hypersensitivity in the maxillary anterior region. 
On examination, Miller's class III recession was seen with 12-22, periodontal pockets with 13-23, vitality test for 11 showed it to be non vital (Fig.1). The treatment plan decided was endodontic treatment for 11, elimination of periodontal pockets this was to be followed by rehabilitation by gingival prosthesis for the maxillary anteriors. The patient first received basic phase 1 therapy, which incorporated scaling, and root planning by ultrasonic and hand instruments followed by oral hygiene instruction.

After 1 week of phase I therapy she was referred to the Department of Conservative dentistry and Endodontics for root canal in respect to 11. The patient underwent flap surgical procedure one month after completion of phase 1 therapy. A conventional flap procedure was selected for 13-23, crevicular incision was placed and a full-thickness periosteal flap was elevated. Debridement was done followed by bone grafting in respect to 11(Fig.2). The flaps were repositioned and sutured using interrupted non-resorbable 4-0 silk suture, the surgical site was covered post operatively with a non-eugenol periodontal dressing for protection (Fig.3).

Aceclofenac (100 mg twice daily) and amoxicillin (500mg thrice a day) was prescribed for 5 days. Postoperative instructions were given and after a week, the periodontal dressing and sutures were removed, and the site was flushed with saline solution.

The patient was referred to the Department of Prosthodontics for the gingival veneer, the master impression was made using buccal approach to incorporate inter proximal details. Wax was used to block lingual embrasures. Final impression was made using polyether impression material in a special fabricated custom tray. The cast was prepared using type IV die stone and a gingival prosthesis was waxed up and processed in heat-cured acrylic resin. Minor inter proximal undercuts was used for retention purpose. To engage these undercuts the prosthesis was made extremely thin and flexible.

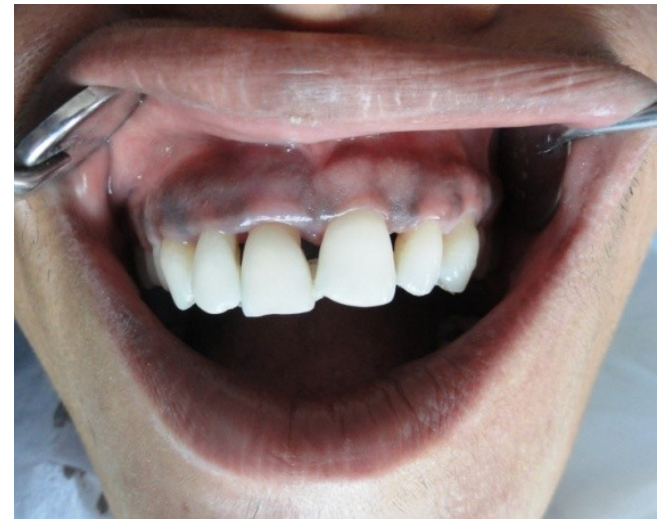

Figure 1: Preoperative

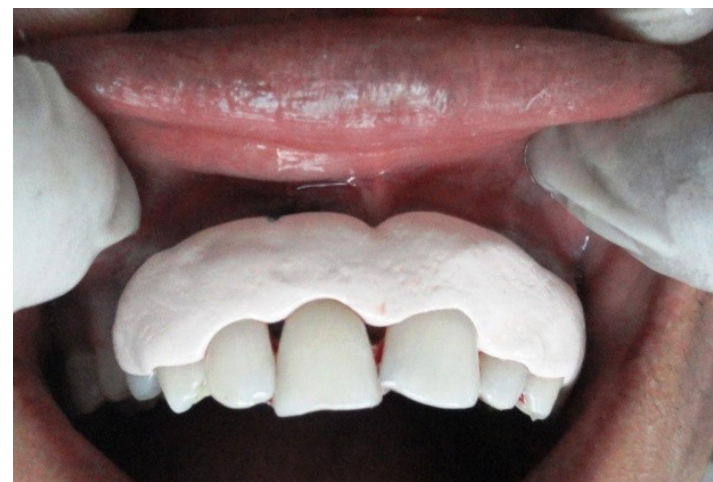

Figure 3: Flaps sutured and periodontal pack placed

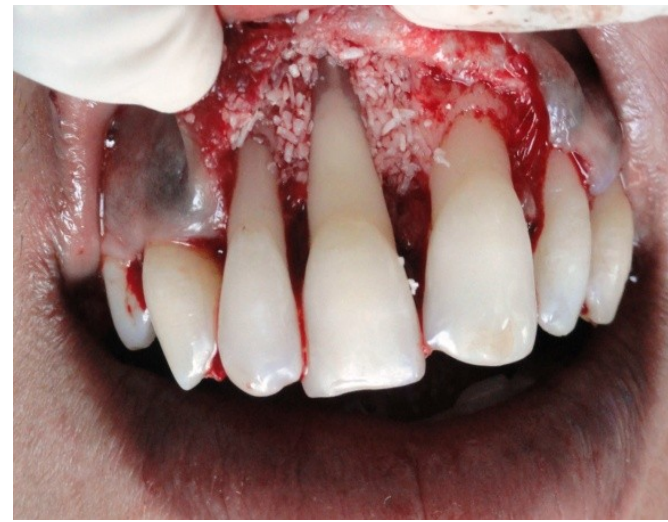

Figure 2: Flap elevated with debridement completed and bone grafting done in respect to 11

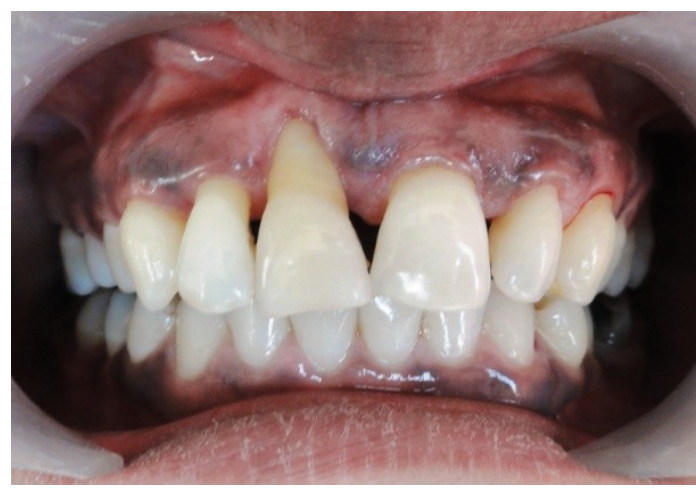

Figure 4: Postoperative, after 2 months 


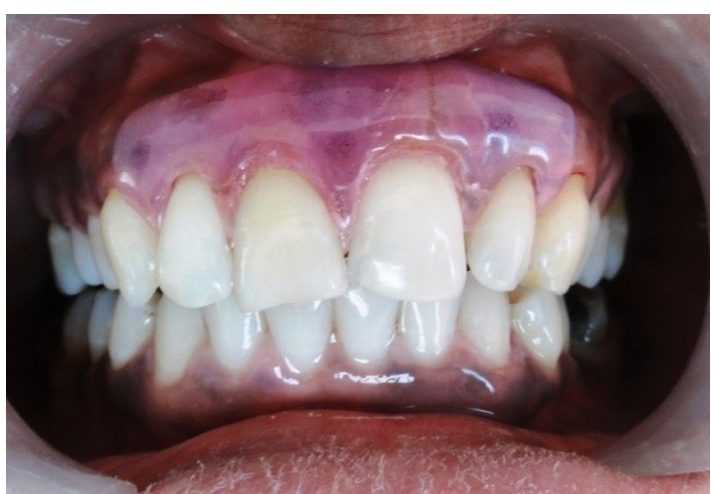

Figure 5: Postoperative, with gingival veneer

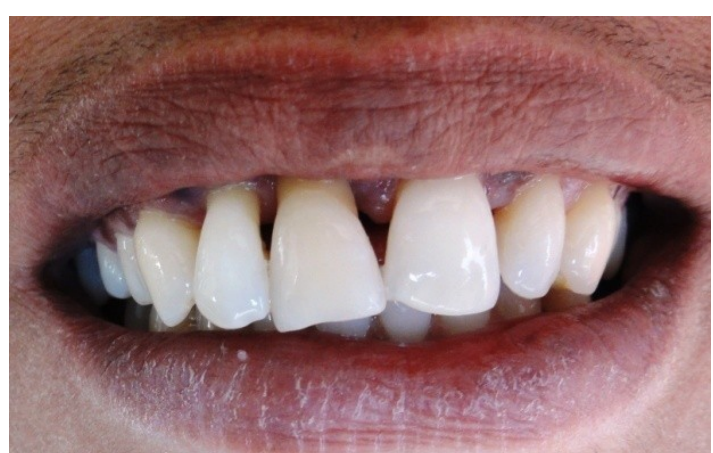

Figure 6: Patient's smile without gingival veneer

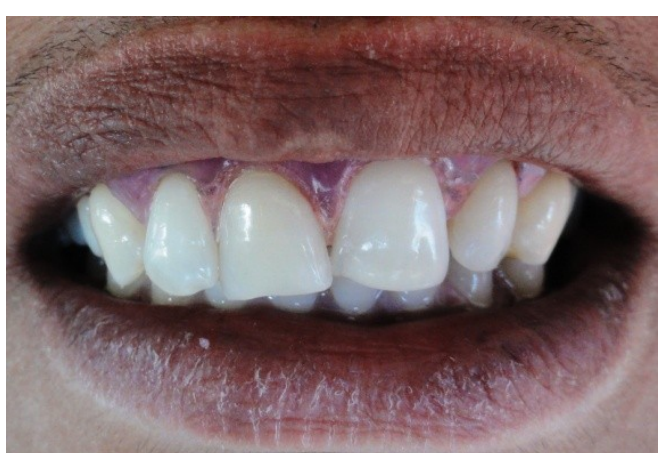

Figure 7: Patient's smile with gingival veneer

\section{Discussion}

Gingival defects can be treated by rebuilding papillae and grafting procedures that may involve not only soft-tissue manipulation but also bone augmentation to support the soft tissue. When small volumes of tissue are being reconstructed then its possible to create esthetically satisfying and anatomically correct tissue contours, but this method is unpredictable when a large volume of tissue is missing. The unpredictability, healing time, discomfort and surgical costs make this option unpopular.

Gingival veneer also known by synonyms such as gingival mask, gingival slip and party gums can provide a quick, simple and inexpensive options for restoring the lost gingival tissues. Soft tissue gingival defects and recession that are created due to periodontal disease progression, pocket elimination procedures and resective osseous surgery can be successfully treated by using these veneers.

In the present case the patient had a compromised periodontal condition in the maxillary anterior region. After phase I, the average probing pocket depth was of $7 \mathrm{~mm}$ with soft consistency gingiva. Pocket elimination and bone grafting was carried out with flap surgery. Two months after the surgery, the gingival became firm and resilient, the probing pocket depth was $3 \mathrm{~mm}$, further gingival recession was seen in respect to 11 reaching up to mucogingival junction, thereby creating a soft tissue defect necessitating the use of gingival prosthesis (Fig.4, Fig.5).

The Gingival veneer is more predictable approach to replace lost tissue architecture, especially a larger amount of tissue needs replacement. They may offer a good interim solution for patients who may wish to have time to consider their options of more advanced and complex treatment.

This prosthesis provides patient with comfort, peace of mind, and boost self confidence but its application is limited to situations where oral hygiene is manageable by the patients. In the present case the prosthesis helped to achieve an esthetic result, decreased hypersensitivity significantly, prevented food lodgment, and improved phonetics (Fig.6, Fig.7).

\section{Conclusion}

Soft tissue defects such as loss of papilla, gingival recession caused by periodontal disease, various pocket elimination and resective osseous surgery can lead to esthetic and functional clinical problems in the maxillary and mandibular anterior region. Such cases offer challenge and test the capability of the clinician in providing patient an esthetic solution for missing gingival tissue as well maintaining hygiene at the same time. Gingival veneer is an effective, inexpensive, treatment modality that offers a predictable solution in restoring lost gingival tissue, particularly when large amount is needed to be replaced, ensuring patient fulfillment esthetically, functionally and psychologically. 


\section{References}

[1]. Mekayarajjnanoth T, Kiat-amnuay S, Sooksuntisakoonchai N, Salinas TJ, The functional and esthetic deficit replaced with an acrylic resin gingival veneer, Quintessence International, 33(2),2002,91-94.

[2]. Ellis SGS, Sharma P, Harris IR, Case report: aesthetic management of a localized periodontal defect with a gingival veneer prosthesis, European Journal of Prosthodont Restorative Dentistry,8(1),2000,23-26.

[3]. Emslie RD, A case of advanced periodontitis complex. Dental Practitioner,5,1955,432-433.

[4]. L'Estrange PR, Strahan JD, The wearing of acrylic periodontal veneers. British Dental Journal ,128,1970,193-194.

[5]. Hickey B, Jauhar S, Gingival veneers. Dental Update, 36,2009,422-428. 